\title{
Effects of Washing and Drying on Crystal Structure and Pore Size Distribution (PSD) of $\mathrm{Zn}_{4} \mathrm{O}_{13} \mathrm{C}_{24} \mathrm{H}_{12}$
}

\section{Framework (IRMOF-1)}

\author{
Mehrzad Arjmandi and Majid Pakizeh ${ }^{\dagger}$ \\ Department of Chemical Engineering, Faculty of Engineering, Ferdowsi University of Mashhad, Mashhad, Iran \\ [Manuscript received 23 February 2013, in revised form 18 May 2013] \\ (C) The Chinese Society for Metals and Springer-Verlag Berlin Heidelberg
}

\begin{abstract}
In this study, the effects of various methods of washing and drying of MOF-5 nanocrystals on structure formation were investigated. Eight samples of MOF-5 were synthesized under different conditions. TGA, XRD and PSD analysis were applied to characterize of the samples. The methods of washing and drying were found to be important in determining the final structure of MOF-5s. MOF-5 with high BET surface area can be obtained by choosing a suitable method of washing and drying. According to the results obtained in this work, it was found that vacuum drying at $425{ }^{\circ} \mathrm{C}$ is sufficient to dissolve the MOF-5-DMF. Similar results were obtained by washing method (with $\mathrm{CH}_{2} \mathrm{Cl}_{2}$ and $\mathrm{CHCl}_{3}$ ), when compared with vacuum drying at $425{ }^{\circ} \mathrm{C}$ according to XRD test. The pore size distribution of samples $1-5$ and 8 were calculated by SHN1 method and results showed that the samples in which solvent vacuum was DMF, have lower pore volume, uniform pore size distribution and the pore size are smaller than samples 3, 4 and 8 . It was also found that activated MOF-5 can be converted to its deactivated form prior to drying of the samples.
\end{abstract}

KEY WORDS: Metal organic framework (MOF); MOF-5 nanocrystal; Characterization; SHN1 method

\section{Introduction}

Metal-organic frameworks (MOFs) have attracted significant attention in recent years for their potential applications in gas storage $e^{[1-3]}$, gas separation ${ }^{[4]}$, drug delivery ${ }^{[5]}$, biomedicine ${ }^{[6]}$, electronics ${ }^{[7]}$ and catalysis $^{[8,9]}$. This kind of material can be thought of as the composition of two major components: a metal ion (or cluster of metal ions) and an organic molecule called a linker (or bridging ligands). A class of MOFs, isoreticular MOFs (IRMOF) share a common cubic topology constructed from linear organic links connecting $\mathrm{Zn}_{4} \mathrm{O}$ clusters as in $\mathrm{Zn}_{4} \mathrm{O}_{13} \mathrm{C}_{24} \mathrm{H}_{12}$ framework named as MOF-5 (i.e. IRMOF-1) which was invented in $1999^{[10]}$. This framework has potential applications for hydrogen storage, $\mathrm{CO}_{2}$ sequestra-

† Corresponding author. Ph.D.; Tel./Fax: +98 5118816840; Email address: pakizeh@um.ac.ir (Majid Pakizeh)

DOI: $10.1007 / \mathrm{s} 40195-013-0105-0$ tion, and catalysts ${ }^{[11-13]}$. Also, functionalization of organic bridges can change the adsorption capacities and surface area ${ }^{[14]}$.

For synthesis of MOF-5, $\mathrm{Zn}\left(\mathrm{NO}_{3}\right)_{2} \cdot 6 \mathrm{H}_{2} \mathrm{O}$ and $\mathrm{H}_{2} \mathrm{BDC}$ were dissolved in a solution DMF and $\mathrm{H}_{2} \mathrm{O}$. After formation of initial crystal are placed under the washing process and then, the crystals are placed under the drying process. The washing of MOF-5, is due to the activation of surface to achieve a very high surface area. It seems that the drying process of the crystals is evaporating of the solvent which is present in the crystal. However, in this study, it is claimed that it will not lead to the formation of MOF-5 nanocrystal. For the MOF-5 synthesis process, washing and drying methods are very crucial. This allows one to tailor MOF structures via selecting solvent during the synthesis. Finally, regarding the TGA, XRD analysis and pore size distribution (PSD) results of synthesized samples the best method for washing and drying of MOF-5 will be presented. 


\section{Experimental}

\subsection{Material}

1,4-Benzenedicarboxylic acid $\left(\mathrm{H}_{2} \mathrm{BDA}\right)(>99 \%)$, zinc nitrate hexahydrate $\left(\mathrm{Zn}\left(\mathrm{NO}_{3}\right)_{2} \cdot 6 \mathrm{H}_{2} \mathrm{O}\right)(>99 \%)$, dichloromethane $\left(\mathrm{CH}_{2} \mathrm{Cl}_{2}\right)(\geq 99.8 \%)$ and chloroform $\left(\mathrm{CHCl}_{3}\right)(99.9 \%)$ were purchased from Sigma-Aldrich and used without purification. $\mathrm{Zn}\left(\mathrm{NO}_{3}\right)_{2} \cdot 6 \mathrm{H}_{2} \mathrm{O}$ was stored under nitrogen atmosphere to reduce exposure to moisture. HPLC grade water and $N, N$ dimethylformamide (DMF) $\left(99.8 \%, \mathrm{H}_{2} \mathrm{O}<0.15 \%\right)$ were obtained from Merck company.

\subsection{Synthesis samples}

Initially for all 8 samples, $\mathrm{Zn}\left(\mathrm{NO}_{3}\right)_{2} \cdot 6 \mathrm{H}_{2} \mathrm{O}(0.45$ $\mathrm{g}, 1.5 \mathrm{mmol})$ and $\mathrm{H}_{2} \mathrm{BDC}(0.083 \mathrm{~g}, 0.5 \mathrm{mmol})$ were dissolved in a solution (49 $\mathrm{mL}$ dimethylformamide $(\mathrm{DMF})$ and $1 \mathrm{~mL} \mathrm{H}_{2} \mathrm{O}$ ) in a $100 \mathrm{~mL}$ round bottom flask. The solution was heated to $70{ }^{\circ} \mathrm{C}$ under strong agitation. The obtained mixture was heated in an oven at $100{ }^{\circ} \mathrm{C}$ for $8 \mathrm{~h}$ to yield large cube-shaped crystals. The reaction vessel was then removed from the oven and allowed to cool to room temperature. After performing these steps the DMF was decanted and the remained solid was repeat washed 6 times (each time is $8 \mathrm{~h}$ ) by $10 \mathrm{~mL} \mathrm{DMF}$ and/or $10 \mathrm{~mL} \mathrm{CH}_{2} \mathrm{Cl}_{2}$, and/or $\mathrm{mL} \mathrm{CHCl}_{3}$, and then dried in vacuum $(13.5 \mathrm{~Pa})$ or atmosphere $\left(1.01 \times 10^{5} \mathrm{~Pa}\right)$ for different time at different temperatures, as according to Table 1.

\subsection{Characterization}

\subsubsection{Powder X-ray diffraction (XRD)}

XRD data was obtained using Philips $X^{\prime}$ pert powder diffractometer (PW3710 model) system with $\mathrm{Cu}$ anode. XRD analysis was performed in the range of $2 \theta$ from $4^{\circ}$ to $40^{\circ}$ at a scan rate of $0.05^{\circ} / \mathrm{s}$.

\subsubsection{Thermogravimetric analysis (TGA)}

Thermogravimetric analysis (TGA) (about $15 \mathrm{mg}$ of MOF-5 samples) was carried out in air at a constant heating rate of $5{ }^{\circ} \mathrm{C} / \mathrm{min}$, using TGA-50 apparatus (Shimadzu, Japan).

\subsubsection{Surface area measurement}

Surface area of the samples Nos.1-5 and No.8 were measured by the Brunauer-Emmett-Teller
(BET) method ${ }^{[14]}$ using nitrogen physical adsorption isotherm at liquid-nitrogen temperature $(77 \mathrm{~K})$.

\subsubsection{Pore size distribution}

Pore size distributions of samples Nos. 1-5 and No.8 were evaluated using the SHN1 method, which was presented by Shahsavand et al. ${ }^{[16]}$ for reliable estimation of the pore size distributions (PSD) of adsorbents based on inverse theory using mere condensation data. Detailed description of this method has been received sufficient attention in this article. A brief review is presented here to familiarize the reader with the proposed method.

The following integral equation is usually used to find the pore size distribution (PSD) of a heterogeneous solid adsorbent $(f(r))$ from the amount of adsorbed material at a given sets of pressures:

$$
Q_{\mathrm{t}}=\int_{0}^{r_{\mathrm{k}}\left(P_{i}\right)} f(r) \mathrm{d} r
$$

The above ill-posed problems of finding $f(r)$ from above integrals can be replaced with a set of linear algebraic equations using a combination of inverse theory and linear regularization technique.

$$
\left(\boldsymbol{R}^{\mathrm{T}} \boldsymbol{R}+\lambda \boldsymbol{B}^{\mathrm{T}} \boldsymbol{B}\right) f=\boldsymbol{R}^{\mathrm{T}} \boldsymbol{Q}
$$

Solving Eq. (2) will lead to obtain pore size distribution $(f(r))$. Also the calculation procedure of matrix $\boldsymbol{R}, \boldsymbol{B}, \boldsymbol{Q}$ and optimum $\lambda$ has been fully described in Ref. [16].

Also the number of rows in matrix $\boldsymbol{R}$ is related to the number of experimental data $(N)$ and the number of columns is equal to multiplication $N$ by the number of discretization in each interval $(M(P))(N \times M(P))$ and $\lambda$ is the regularization parameter.

The precision and validity of SHN1 method have been investigated for several experimental data and the results have been compared with other methods and obtained results have confirmed the precision of SHN1 method.

\section{Results and Discussion}

\subsection{XRD analysis}

In this study, the various synthesis methods of MOF-5 were investigated. The MOF-5 is character-

Table 1 Washing and drying processes for different samples

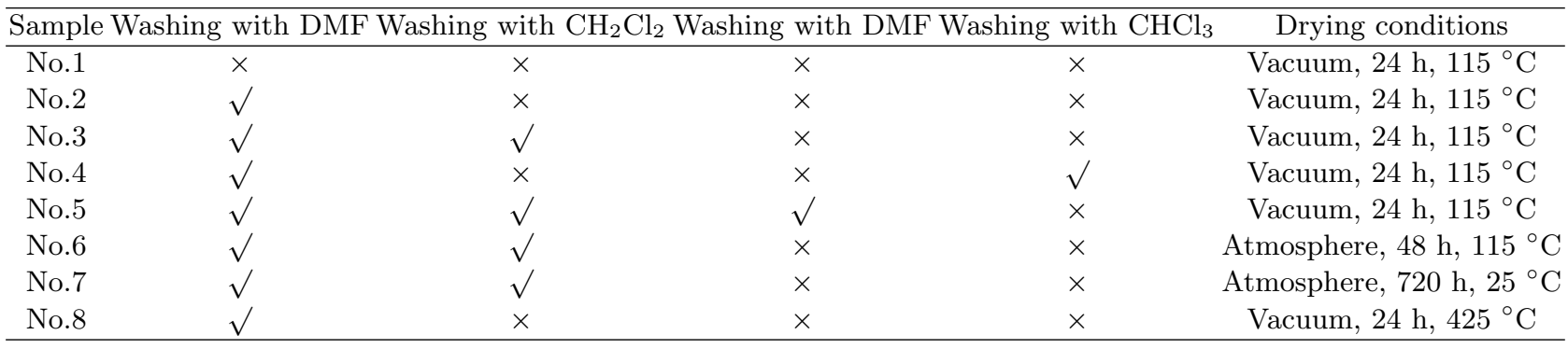




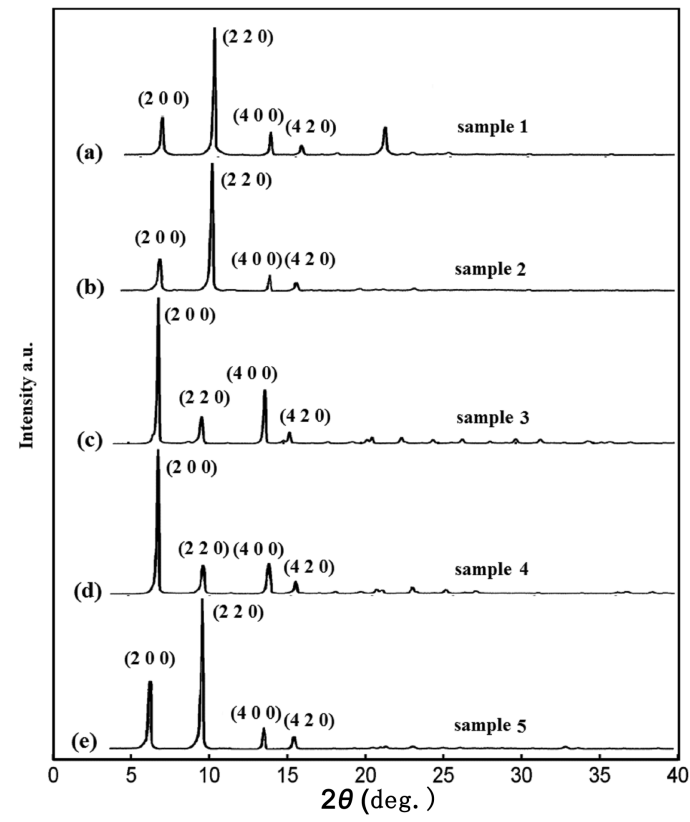

Fig. 1 X-ray diffraction pattern for samples No.1 (a), No.2 (b), No.3 (c), No.4 (d), No.5 (e)

ized by reflection at $\left(\begin{array}{lll}2 & 0 & 0\end{array}\right),\left(\begin{array}{lll}2 & 2 & 0\end{array}\right),\left(\begin{array}{lll}4 & 0 & 0\end{array}\right)$ and $\left(\begin{array}{ll}4 \\ 2\end{array}\right.$ $20)$ conditions $^{[17,18]}$. To evaluate the effect of different washing methods, XRD patterns of Nos.1-5 samples are shown in Fig. 1. All samples were dried in vacuum conditions. According to Fig. 1, among the 5 samples, samples No.1, No.2 and No.5, and also samples No.3 and No.4 have similar XRD patterns. For the No.1, No.2 and No.5 samples, the reflection is at $2 \theta \approx 9.5^{\circ}$. Which was more intense than that at $2 \theta \approx 6.8^{\circ}$. In the case of samples No.3 and No.4, the reflection at $2 \theta \approx 6.8^{\circ}$. was more intense than the reflection at $2 \theta \approx 9.5^{\circ}$. However, all five samples exhibit four main peaks belonging to MOF-5. According to some interesting articles ${ }^{[18,19]}$, if the reflection at $2 \theta \approx 9.5^{\circ}$. was more intense than the reflection at $2 \theta \approx 6.8^{\circ}, \mathrm{MOF}-5$ with high surface area will be obtained.

XRD patterns of samples No.1 and No.2 were similar, because the solvent vacuumed for these samples was DMF and therefore had low BET surface area (see the results and discussion in nitrogen adsorption analysis section). It is believed that guest molecules ( $\mathrm{ZnO}$ species and DMF molecules) occupied pores of samples No.1 and No.2 and caused a destructive interference in the XRD pattern and, through washing, these molecules were removed ${ }^{[18-21]}$. Zhang and $\mathrm{Hu}^{[18]}$ showed that the filling pores by $\mathrm{ZnO}$ did not cause structural distortion of MOF-5. Therefore, it seems that the solvent used in washing is very important. Usually surface washing of the MOF-5, is due to the activation surface to achieve a very high surface area. This showed that the DMF was not a good solvent for activating MOF-5. But according to the XRD patterns for samples No.3 and No.4, it is clear that $\mathrm{CH}_{2} \mathrm{Cl}_{2}$ and $\mathrm{CHCl}_{3}$ are good solvents for washing and activating MOF-5 nanocrystal. Also, ac- cording to the XRD pattern for sample 5 , it can be found that activated MOF-5 before vacuum can be deactivated by rewashing by DMF. The comparison of XRD patterns for the five samples (Fig. 1) indicated that crystal structure of MOF-5 framework that were dried in vacuum had very high sensitivity to the type of solvent.

It can concluded that only dissolving of $\mathrm{Zn}\left(\mathrm{NO}_{3}\right)_{2} \cdot 6 \mathrm{H}_{2} \mathrm{O}$ and $\mathrm{H}_{2} \mathrm{BDC}$ mixture in a solution of DMF and $\mathrm{H}_{2} \mathrm{O}$ did not lead to the formation of MOF5 nanocrystal. On the other hand, all samples were synthesized in the same conditions and from same raw materials but the different XRD patterns were obtained which is due to different washing routes.

To investigate the effect of different drying methods, samples No.3, No.6 and No.7 were synthesized in different drying conditions. Their XRD patterns were shown in Fig. 1(c) and Fig. 2(a) and (b), respectively. Drying process is designed to remove excess solvent. Therefore, it is expected to obtain a powder MOF-5 by all three methods with the same features. But, XRD patterns for the dry samples No.3, No.6 and No.7 show that only sample No.3 has a common crystalline structure of MOF-5 (Fig. 1(c)) because this sample exhibits four main peaks belonging to MOF5 , meaning that for the drying process, in addition to temperature, pressure can be also important. Sample No.3 was dried under vacuum condition and was common nanocrystal MOF-5. But, sample 6 was dried at atmospheric pressure and, despite temperature was $115{ }^{\circ} \mathrm{C}$, it was different from the common MOF-5 nanocrystal (Fig. 2(a)). Sample No.7 was dried at ambient pressure and temperature conditions. Although drying time was very long for this sample, it was different from the common MOF-5 nanocrystal (Fig. 2(b)). As shown in Fig. 2, four main peaks of MOF-5 were not appeared in the case of samples No.6 and No.7. Other peaks emerged in these two latter samples can be attributed to guest molecules in the framework of MOF-5.

However, as mentioned above, all the Nos.1-5 samples were dried in vacuum. But, their structures were different from each other because different solvents were used for washing. Due to the XRD patterns for samples Nos.1-5, it is clear that, among the existing solvents, DMF showed a different behavior. Before drying in vacuum, DMF was subject to MOF-5; then, DMF was trapped with more power in the structure of MOF-5. This occupied the pores and reduced the surface of MOF-5 ${ }^{[18,19]}$. In other word, samples No.1, No.2 and No.5 were called MOF-5-DMF. The XRD patterns for samples 3 and 4 showed that, by washing and soaking MOF-5-DMF with various solvents such as $\mathrm{CH}_{2} \mathrm{Cl}_{2}$ and $\mathrm{CHCl}_{3}$, MOF-5 nanocrystal with high surface area can be produced. Trapping DMF molecules within the pores of a new metal organic framework and exchange with methanol, ethanol, benzene, and cyclohexane has reported recently by Zeng et. al ${ }^{[22]}$. 


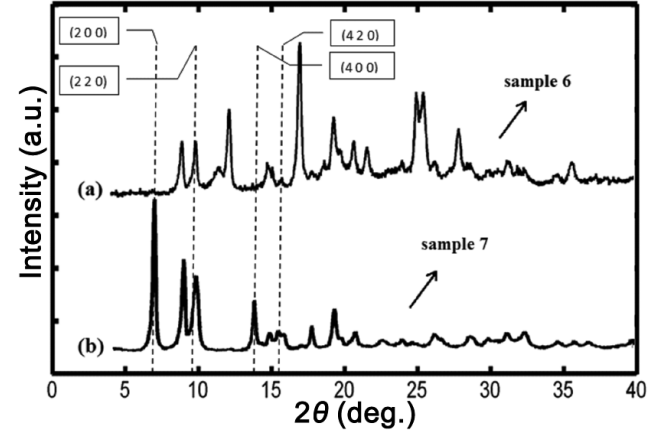

Fig. 2 X-ray diffraction pattern for samples No.6 (a) and No.7 (b)

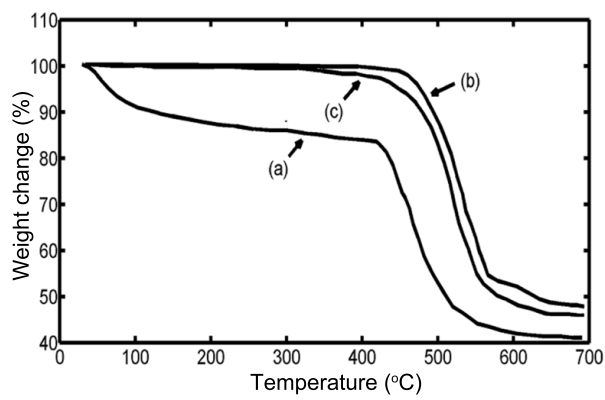

Fig. 3 Thermogravimetric curves of sample No.2 (a), sample No.3 (b) and sample No.8 (c)

\subsection{TGA Analysis}

TGA analysis results of samples No.2, No.3 and No.8 are given in Fig. 3. As it can be seen in Fig. 3(a), the weight loss at initial stages $\left(25-100{ }^{\circ} \mathrm{C}\right)$ is due to evaporation of the physically adsorbed solvents molecules which is not seen for samples No.3 and No.8. Also the weight loss in 100 to $425^{\circ} \mathrm{C}$ range, DMF desolvation is occurred for sample No.2. In other words, MOF-5 nanocrystal was the product of thermal desolvation of MOF-5-DMF. Before the desolvation, carbonyl groups of the DMF molecules were associated with the zinc atoms of the MOF-5 framework. Thermal gravimetric analysis demonstrated that DMF molecules detached from the apical position on the zinc atoms above $425^{\circ} \mathrm{C}^{[18]}$.

The TGA result in Fig. 3(c) suggested that drying in vacuum at $425{ }^{\circ} \mathrm{C}$ is sufficient to dissolve the MOF-5-DMF. Similar results were obtained by washing with $\mathrm{CH}_{2} \mathrm{Cl}_{2}$ and $\mathrm{CHCl}_{3}$, when compared with vacuum drying at $425{ }^{\circ} \mathrm{C}$ (Fig. 3(b). Also, according to TGA and XRD analysis of sample No.8 (as shown in Fig. 4 and Fig. $3(\mathrm{c})$ ), the reflection at $2 \theta \approx 6.8^{\circ}$. was more intense than the reflection at $2 \theta \approx 9.5^{\circ}$. By comparing XRD patterns of sample No.3 and No.8, it can be said that structures of these materials are the same although washing solvent were different. It should be noted that MOF-5 nanocrystal of sample No.8 was dried at $425{ }^{\circ} \mathrm{C}$ under vacuum condition after washing with DMF.

\subsection{Nitrogen adsorption analysis}

Fig. 5 shows the nitrogen adsorption isotherms at $77 \mathrm{~K}$ for the samples Nos.1-5 and No.8. According to

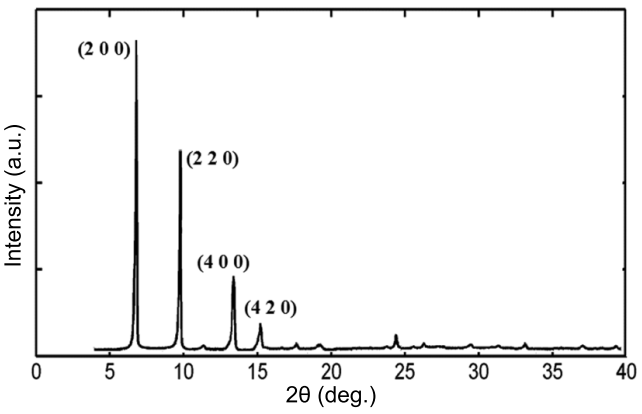

Fig. 4 X-ray diffraction pattern of sample No.8

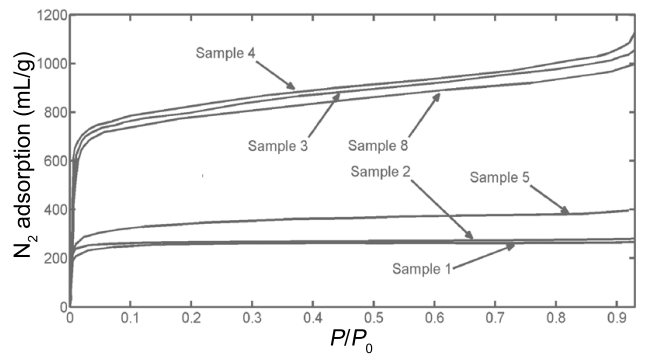

Fig. $5 \mathrm{~N}_{2}$ adsorption isotherms at $77 \mathrm{~K}$ for Nos.1-5 and No.8 samples ( $P$ is the pressure of $\mathrm{N}_{2}, P_{0}$ $\left.=1.01 \times 10^{5} \mathrm{~Pa}\right)$

Fig. 5, the samples No.3, No.4 and No.8 are have the similar adsorption isotherms. As well as the samples No.1, No.2 and No.5 are have the similar adsorption isotherms. Adsorption isotherms for the 6 samples justified the results of XRD patterns.

The BET surface areas of the samples Nos.1-5 and No.8 that were estimated from the nitrogen adsorption are $743,912,2800,2960,1320$ and $2635 \mathrm{~m}^{2} / \mathrm{g}$, respectively. As expected above, the BET surface areas of the samples No.3, No.4 and No.8 are much higher than others, this MOF-5 is called cubic MOF-5 $\left.{ }^{[23}\right]$. Also for samples No.1, No.2 and No.5, the solvent is DMF, and DMF molecules trapped within the pores in these samples and have lower surface. This MOF-5 is called tetragonal MOF-5 ${ }^{[24]}$.

\subsection{Pore size distribution (PSD) analysis}

Pore size distributions of as prepared MOF-5 materials (samples Nos.1-5 and No.8) were depicted in Fig. 6 using SHN1 method. The pore textural properties and more information of these six samples were summarized in Table 2. According to the Table 2 and Fig. 6, the BET surface areas of the samples No.1, No.2 and No.5 are less than those of the samples No.3, No.4 and No.8. By considering the previous contents and the molecular size of DMF $(\sim 0.6 \mathrm{~nm})^{[25]}$, it can be expected that the larger pores in the samples No.1, No.2 and No.5 are filled with DMF molecules. The DMF molecule is smaller than the average pore size of the 6 samples. There is a speculation that in addition to blocking some smaller pores, DMF also makes changes in the larger pore size. 
Table 2 BET surface area of different samples and the mean pore radius and mean pore volume in different samples

\begin{tabular}{cccc}
\hline Sample & $S_{\text {BET }}\left(\mathrm{m}^{2} / \mathrm{g}\right)$ & Mean pore radius $(\mathrm{nm})$ & Mean pore volume $(\mathrm{mL} / \mathrm{g})$ \\
\hline No.1 & 743 & 0.8285 & 0.446 \\
No.2 & 912 & 0.8139 & 0.391 \\
No.3 & 2800 & 0.9642 & 1.213 \\
No.4 & 2960 & 0.8951 & 1.497 \\
No.5 & 1320 & 0.7810 & 0.411 \\
No.8 & 2635 & 0.9293 & 1.141 \\
\hline
\end{tabular}

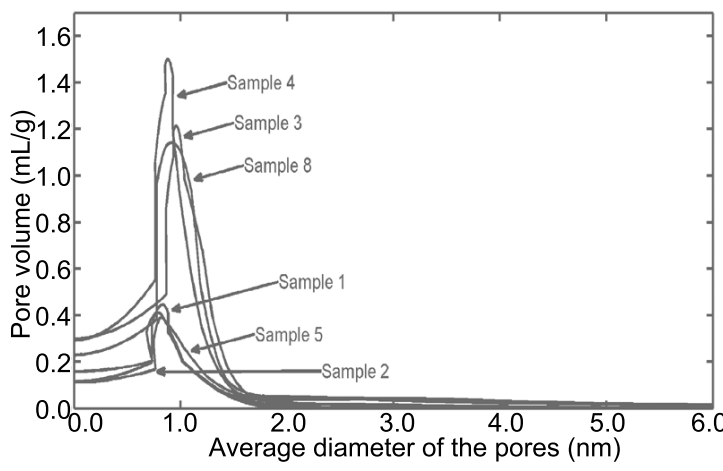

Fig. 6 Pore size distribution (PSD) of samples Nos.1-5 and No.8 (obtained by SHN1 method)

\section{Conclusions}

In this study, using various methods of washing and drying, eight samples were successfully synthesized. Comparisons among XRD patterns for the all prepared samples showed that only dissolving of $\mathrm{Zn}\left(\mathrm{NO}_{3}\right)_{2} \cdot 6 \mathrm{H}_{2} \mathrm{O}$ and $\mathrm{H}_{2} \mathrm{BDC}$ mixture in a solution of DMF and $\mathrm{H}_{2} \mathrm{O}$ did not lead to the formation of MOF5 nanocrystal. It was found that to achieve the common MOF-5 structure, the selection of washing and drying method is very important. Studies with different methods of washing have shown that, by choosing different solvents, different MOF-5 structures can be obtained. Also, according to the XRD pattern for sample No.5, before the drying process by replacing the washing solvent, MOF-5 surface can be turned from active into inactive. The pore size distribution of samples Nos.1-5 and No.8 showed that these samples that were washed by DMF and dried in vacuum have lower BET surface area and more uniform pore size distribution. Presence of DMF in MOF-5 structure may block some small pores and also reduces the size of the large pores.

\section{REFERENCES}

[1] M. Dinca and J.R. Long, Angew. Chem. Int. Ed. 47 (2008) 6766.

[2] N.L. Rosi, J. Eckert, M. Eddaoudi, D.T. Vodak, J. Kim, M. O'Keeffe and O.M. Yaghi, Science 300 (2003) 1127.

[3] J.W. Yoon, Y.K. Seo, Y.K. Hwang, J.S. Chang, H. Leclerc, S. Wuttke, P. Bazin, A. Vimont, M. Daturi, E. Bloch, P.L. Llewellyn, C. Serre, P. Horcajada, J.M. Greneche, A.E. Rodrigues and G. Ferey, Angew. Chem. Int. Ed. 49 (2010) 5949.
[4] R.J. Kuppler, D.J. Timmons, Q.R. Fang, J.R. Li, T.A. Makal, M.D. Young, D.Yuan, D. Zhao,W. Zhuang and H.C. Zhou, Coord. Chem. Rev. 253 (2009) 3042.

[5] R.C. Huxford, J.D. Rocca and W. Lin, Curr. Opin. Chem. Biol. 14) (2010) 262.

[6] J.Y. An, S.J. Geib and N.L. Rosi, J. Am. Chem. Soc. 131 (2009) 8376.

[7] G. de Combarieu, M. Morcrette, F. Millange, N. Guillou, J. Cabana, C.P. Grey, I. Margiolaki, G. Ferey and J.M. Tarascon, Chem. Mater. 21 (2009) 1602.

[8] Y.K. Hwang, D.Y. Hong, J.S. Chang, S.H. Jhung, Y.K. Seo, J. Kim, A. Vimont, M. Daturi, C. Serre and G. Ferey, Angew. Chem. Int. Ed. 47 (2008) 4144.

[9] L.F. Yang, S. Kinoshita, T. Yamada, S. Kanda, H. Kitagawa, M. Tokunaga, T. Ishimoto, T. Ogura, R. Nagumo, A. Miyamoto and M. Koyama, Angew. Chem. Int. Ed. 49 (2010) 5348.

[10] H. Li, M. Eddaoudi, M. O'Keeffe and O.M. Yaghi, Nature 402 (1999) 276

[11] M. Muller, S. Hermes, K. Kaehler, M.W.E. van de Berg, M. Muhler and R.A. Fischer, Chem. Mater. 20 (2008) 4576.

[12] F. Salles, H. Jobic, G. Maurin, M.M. Koza, P.L. Llewwellyn, T. Devic, C. Serre and G. Férey, Phys. Rev. Lett. 100 (2008) 245901.

[13] J.S. Choi, W.J. Son, J. Kim, and W.S. Ahn, Microporous Mesoporous Mater. 116 (2008) 727.

[14] F. Sun, Z. Yin, Q. Q. Wang, D. Sun, M. Zeng and M. Kurmoo, Angew. Chem. Int. Ed. 52 (2013) 4538.

[15] S. Brunauer, P.H. Emmett and E. Teller, J. Am. Chem. Soc. 60 (1938) 309.

[16] A. Shahsavand and M.N. Shahrak, Colloids Surf. A 378 (2011) 1.

[17] Z. Jia, H. Li, Zh. Yu, P. Wang and X. Fan, Mater. Lett. 65 (2011) 2445.

[18] L. Zhang and Y.H. Hu, Mater. Sci. Eng. B 176 (2011) 573.

[19] E.V. Perez, K.J. Jr Balkus, J.P. Ferraris and I.H. Musselman, J. Membr. Sci. 328 (2009) 165.

[20] T. Mueller, M. Schubert, F. Teich, H. Puetter, K. Schierle-Arndt and J. Pastre, J. Mater. Chem. 16 (2005) 626.

[21] A.R. Millward and O.M. Yaghi, J. Am. Chem. Soc. 127 (2005) 17998.

[22] M. Zeng, Y.Tan, Y. He, Z. Yin, Q. Chen and M. Kurmoo, Inorg. Chem. 52 (2013) 2353.

[23] S.S. Kaye, A. Dailly, O.M. Yaghi and J.R. Long, J. Am. Chem. Soc. 129 (2007) 14176.

[24] L. Huang, H. Wang, J. Chen, Z. Wang, J. Sun, D. Zhao and Y. Yan, Microporous Mesoporous Mater. 58 (2003) 105.

[25] E. S. Boes 1, P. R. Livotto and H. Stassen, Chem. Phys. 331 (2006) 142. 